\title{
Nationwide Benchmarking of Hand Hygiene Performance
}

\author{
Benedetta Allegranzi, MD; ${ }^{1}$ Andrew Stewardson, MBBS; ${ }^{2}$ Didier Pittet, MD, MS ${ }^{1,2}$
}

(See the article by Behnke et al, on pages 618-620.)

Hand hygiene promotion is key to patient safety and a cornerstone of effective healthcare-associated infection prevention efforts. ${ }^{1}$ Many healthcare settings worldwide have committed to the implementation of hand hygiene campaigns with set targets for improvement. ${ }^{2,3}$ Evaluation of these strategies, especially by performance monitoring and infrastructure indicators, is a critical element to their success. This provides managers with information on the impact of campaign implementation and healthcare workers with feedback to motivate and sustain behavior change. Several countries have recently taken up this challenge at national level and included hand hygiene in quality improvement goals and indicators. ${ }^{4-6}$

In this issue, Behnke et $\mathrm{al}^{7}$ present alcohol-based hand rub (ABHR) consumption data collected prospectively on a voluntary basis through the German national nosocomial infection surveillance system ${ }^{8}$ since January 2008 . Hospitals report data to a centralized system stratified by type of ward (intensive care unit [ICU] and non-ICU) and specialty. The overall objective is to facilitate improvement through both intrahospital (ie, between wards) and interhospital benchmarking. Established in 2008, the national German hand hygiene campaign ${ }^{5}$ includes more than 900 healthcare settings and is one of the largest worldwide. In line with the World Health Organization (WHO) hand hygiene improvement strategy, participating facilities are requested to (1) secure the active support of administrators; (2) participate in a 1-day introductory course, national workshops, and a national hand hygiene day; (3) organize training of healthcare workers at least once a year; (4) increase ABHR availability, monitor its consumption, and provide feedback; and (5) implement the WHO's My 5 Moments for Hand Hygiene model. ${ }^{1,9}$ Considering the broad national scope, these features and organization are exceptional, particularly the nationwide ABHR consumption data collection system. Behnke et $\mathrm{al}^{7}$ report the 4-year results for a sample of 152 hospitals and show a $40.9 \%$ and $27.2 \%$ increase in median ABHR consumption per patient-day in ICUs and non-ICUs, respectively. Although such increases may be easily achieved in institutions where $A B H R$ is newly introduced and replaces hand washing, these are astonishing in a context where ABHR was widely available for many years before the start of the national campaign. This dramatic increase strongly supports the effectiveness of the multimodal promotion strategy, particularly the performance feedback provided. However, establishing whether this increase reflects actual hand hygiene compliance improvement remains challenging.

ABHR consumption measurement was chosen as a surrogate parameter for hand hygiene performance in Germany because direct observation of compliance was considered resource demanding and unfeasible over long periods. This choice was possible as the vast majority of hand hygiene actions in German hospitals involve ABHR, a crucial prerequisite for the use of its consumption as a surrogate of compliance. On the basis of 2010 ABHR consumption results, the reported estimates of the median number of hand hygiene actions per patient-day are low compared with that reported in the literature and would suggest defective hand hygiene behavior. Although the authors emphasize the existence of a good correlation between ABHR consumption and hand hygiene compliance rates reported elsewhere, their results are controversial and raise concerns about the ultimate outcome of hand hygiene promotion.

ABHR consumption as a surrogate marker for hand hygiene compliance has several limitations. First, there is a need for accurate validation of consumption data entered in the system. Second, as recognized by Behnke and colleagues, consumption does not allow estimates of hand hygiene performance according to actual opportunities and is vulnerable to the influence of unnecessary hand hygiene actions by healthcare workers, use for other purposes (eg, surface disinfection), and use by patients and visitors. Hand hygiene compliance

Affiliations: 1. First Global Patient Safety Challenge, Patient Safety Program, World Health Organization, Geneva, Switzerland; 2. Infection Control Program and World Health Organization Collaborating Center on Patient Safety, University of Geneva Hospitals and Faculty of Medicine, Geneva, Switzerland.

Received March 5, 2012; accepted March 11, 2012; electronically published April 19, 2012.

(C) World Health Organization 2012. All rights reserved. The World Health Organization has granted the publisher permission for the reproduction of this article. 0899-823X/2012/3306-0013\$15.00. DOI: $10.1086 / 665720$ 
monitoring through direct observation provides a much more accurate evaluation of staff practices at the point of care and allows an analysis of compliance stratified by healthcare worker profession or hand hygiene indication. As widely documented, ${ }^{1}$ healthcare workers usually overestimate their own compliance level with hand hygiene recommendations. We strongly believe in the unique power of direct observation data feedback to convince staff, including senior professionals, of the need for performance improvement and to motivate them to achieve and sustain best practice targets. Furthermore, public reporting-or at least feedback of performance data to administrators and government representatives-helps maintain commitment to action, support, and resource allocation. If observational surveys are conducted periodically, the potential observation bias and the so-called Hawthorne effect can be mitigated by the frequent and unobtrusive presence of observers and thus distributed equally among all observations. Furthermore, while conducting frequent observations, this effect can be used deliberately to stimulate hand hygiene compliance with a promotional intention. ${ }^{10}$

Germany is not the only country where ABHR consumption is used as a national surrogate marker for hand hygiene performance. In France, each hospital is allocated an annual individualized target for ABHR consumption on the basis of their activities. The ratio of actual consumption to the target consumption, expressed as a percentage, is used as an indicator of infection prevention practice implementation. ${ }^{11}$ Hospital participation is mandatory, and results have been reported publicly since $2005 .^{5,11,12}$ In a WHO survey conducted in 2009 among 29 national and subnational hand hygiene campaigns worldwide, ABHR consumption was monitored in 19 campaigns (65\%), while hand hygiene compliance observation was reported by $22(76 \%){ }^{6}$ Several national programs have indeed accepted the challenge of regular hand hygiene compliance monitoring by direct observation according to the WHO's My 5 Moments approach and public reporting. ${ }^{1,5,13}$ Among the latter, Hand Hygiene Australia ${ }^{14}$ collects such data from public and private hospitals nationwide and reports aggregated national data online. Observers enter hand hygiene compliance results directly into the national database using an innovative web-based data-entry application via Internet browsers or web-enabled mobile devices. ${ }^{15,16}$ According to data from 521 Australian hospitals, a significant increase in hand hygiene compliance from 2009 to 2010 was associated with a significant decline in the incidence of methicillin-resistant Staphylococcus aureus bacteremia nationwide. ${ }^{16}$ Although these findings do not permit a definitive causal association, this example demonstrates the feasibility of compliance monitoring and reporting at the national level. In addition, a new initiative was introduced in February 2012 whereby each hospital's hand hygiene compliance result is publicly available online (http://www .MyHospitals.gov.au).

At a recent meeting convened by the European Centre for
Disease Prevention and Control, the idea of establishing a European surveillance network of hand hygiene compliance and ABHR consumption was welcomed by participants from $\mathrm{Eu}$ ropean Union/European Economic Area countries. The wide participation in the 2010 WHO call for worldwide data collection on compliance with the moment 1 indication for hand hygiene - that is, before touching a patient-demonstrates that international monitoring of this indicator by using a standardized method is feasible. ${ }^{17}$

The establishment of a national surveillance system for ABHR consumption is a major achievement within the German system and an opportunity to integrate an infrastructure indicator with outcome measurements. Many more countries should follow this example. However, the best approach to assessing hand hygiene practices and tracking behavioral change over time remains direct observation of practices at the point of care. WHO has developed a validated method ${ }^{13}$ and a range of tools for data detection and observer training ${ }^{18}$ that are currently used in many countries. Repeated, regular compliance monitoring is feasible, even at the national level. Innovative systems for automatic monitoring offer new perspectives with little human resources and expertise investment, but these still need to be validated against the gold standard of direct monitoring. Ideally, the combination of these indicators should be monitored both locally and on a large scale to provide the most accurate evaluation of hand hygiene improvement efforts.

\section{ACKNOWLEDGMENTS}

Financial support. A.S. and D.P. acknowledge recent funding by subsidy 3200B0-122324/1 from the Swiss National Science Foundation for partial support for hand hygiene research activities.

Potential conflicts of interest. All authors report no conflicts of interest relevant to this article. All authors submitted the ICMJE Form for Disclosure of Potential Conflicts of Interest, and the conflicts that the editors consider relevant to this article are disclosed here.

Address correspondence to Didier Pittet, MD, MS, Director, Infection Control Program and World Health Organization Collaborating Center on Patient Safety, University of Geneva Hospitals and Faculty of Medicine, 4 rue Gabrielle Perret-Gentil, 1211 Geneva 14, Switzerland (didier.pittet@ hcuge.ch).

The World Health Organization takes no responsibility for the information provided or the views expressed in this article.

\section{REFERENCES}

1. World Health Organization (WHO). WHO Guidelines on Hand Hygiene in Health Care. Geneva: WHO, 2009.

2. Allegranzi B, Storr J, Dziekan G, Leotsakos A, Donaldson L, Pittet D. The First Global Patient Safety Challenge "Clean Care is Safer Care": from launch to current progress and achievements. J Hosp Infect 2007;65(suppl 2):115-123.

3. Stewardson A, Allegranzi B, Sax H, Kilpatrick C, Pittet D. Back to the future: rising to the Semmelweis challenge in hand hygiene. Future Microbiol 2011;6:855-876.

4. Magiorakos AP, Suetens C, Boyd L, et al. National hand hygiene 
campaigns in Europe, 2000-2009. Euro Surveill 2009;14: pii19190.

5. Magiorakos AP, Leens E, Drouvot V, et al. Pathways to clean hands: highlights of successful hand hygiene implementation strategies in Europe. Euro Surveill 2010;15:pii19560.

6. Mathai E, Allegranzi B, Kilpatrick C, Bagheri Nejad S, Graafmans W, Pittet D. Promoting hand hygiene in healthcare through national/subnational campaigns. J Hosp Infect 2011;77: 294-298.

7. Behnke M, Gastmeier P, Geffers C, Mönch N, Reichardt C. Establishment of a national surveillance system for alcoholbased hand rub consumption and change in consumption over 4 years. Infect Control Hosp Epidemiol 2012;33:618-620 (in this issue).

8. Gastmeier P, Sohr D, Schwab F, et al. Ten years of KISS: the most important requirements for success. J Hosp Infect 2008; 70(suppl 1):11-16.

9. Sax H, Allegranzi B, Uçkay I, Larson E, Boyce J, Pittet D. "My five moments for hand hygiene": a user-centred design approach to understand, train, monitor and report hand hygiene. J Hosp Infect 2007;67:9-21.

10. Allegranzi B, Pittet D. Hand hygiene. In: Fraise A, ed. Principles and Practice of Disinfection, Preservation and Sterilization. 5th ed. Oxford: Wiley, 2012 (forthcoming).

11. Ministère du travail, de l'emploi et de la santé. Rapport national
2010 sur le tableau de bord des infections nosocomiales. http:// www.sante.gouv.fr/IMG/pdf/rapportnational2010_2011def.pdf. Published November 2011. Accessed February 25, 2012.

12. Haustein T, Gastmeier P, Holmes A, et al. Use of benchmarking and public reporting for infection control in four high-income countries. Lancet Infect Dis 2011;11:471-481.

13. Sax H, Allegranzi B, Chraïti M-N, Boyce J, Larson E, Pittet D. The World Health Organization hand hygiene observation method. Am J Infect Control 2009;37:827-834.

14. Grayson ML, Russo PL. The national hand hygiene initiative. Med J Aust 2009;191:420-421.

15. Russo PL, Heard K, Cruickshank M, Grayson ML. The development of an online database and mobile web application for the collection and analysis of hand hygiene compliance data. BMC Proc 2011;5(suppl 6):O30.

16. Grayson ML, Russo PL, Cruickshank M, et al. Outcomes from the first 2 years of the Australian National Hand Hygiene Initiative. Med J Aust 201 1;195:615-619.

17. World Health Organization. Hand hygiene moment 1 -global observation survey: summary report 2010. http://www.who.int /gpsc/5may/news/ps_momentl_results_2010_en.pdf. Published 2010. Accessed February 25, 2012.

18. World Health Organization. Tools for evaluation and feedback. http://www.who.int/gpsc/5may/tools/evaluation_feedback/en/. Published 2009. Accessed February 25, 2012. 